\title{
PERAN MASYARAKAT DALAM PENGENDALIAN KEBAKARAN HUTAN DI BKPH SLARANG KPH PEMALANG
}

\author{
The Role of Community in Forest Fire Prevention at BKPH Slarang, \\ KPH Pemalang
}

\author{
Bambang Hero Saharjo $^{1 *}$ dan Yulia Eka Nurjanah ${ }^{2}$
}

(Diterima 22 Maret 2021 /Disetujui 23 Juni 2021)

\begin{abstract}
Forest fires are a form of forest disturbance that often occurs. Every year, forest fires in Indonesia occur during the dry season. The causes of forest fires in Indonesia are natural and human factors. Forest fires cause an enormous loss in properly controlling forest fires. This study aims to analyze the factors that cause forest fires and examine the efforts to control forest fires and the role of community participation in forest fire control at BKPH Slarang, KPH Pemalang, Central Java. The highest forest fires occurred in 2015 with a frequency of 4 times that the total area of land burned was 11,10 hectares. Forest fire in BKPH Slarang caused a loss of costing IDR 50,234,000. The form of control exercised by BKPH is socialization or counseling about fires. Direct socialization or counseling is given to the community in various activities. Community participation is very high in prevention and blackout activities at BKPH Slarang KPH Pemalang.
\end{abstract}

Key words: BKPH Slarang, causative factors, community participation, control of forest fire.

\begin{abstract}
ABSTRAK
Kebakaran hutan merupakan salah satu bentuk gangguan hutan yang sering terjadi. Kebakaran hutan di Indonesia setiap tahunnya sering terjadi saat musim kemarau. Faktor penyebab kebakaran hutan di Indonesia yaitu disebabkan oleh faktor alam dan faktor manusia. Kebakaran hutan menimbulkan kerugian yang besar apabila tidak dilakukan pengendalian kebakaran hutan dengan baik. Penelitian ini bertujuan menganalisis faktor penyebab terjadinya kebakaran hutan dan mengkaji upaya dalam pengendalian kebakaran hutan serta partisipasi masyarakat dalam pengendalian kebakaran hutan di BKPH Slarang, KPH Pemalang, Jawa Tengah. Kebakaran hutan tertinggi terjadi pada tahun 2015 dengan frekuensi 4 kali serta luas total lahan yang terbakar 11,10 Ha. Kebakaran hutan di BKPH Slarang tersebut menyebabkan kerugian sebesar Rp50.234.000. Bentuk pengendalian yang dilakukan oleh pihak BKPH Slarang yaitu sosialisasi atau penyuluhan mengenai kebakaran. Sosialisasi atau penyuluhan langsung tersebut diberikan kepada masyarakat dalam berbagai kegiatan. Peran masyarakat dalam pengendalian kebakaran hutan di BKPH Slarang sangat tinggi dalam pencegahan maupun pemadaman di BKPH Slarang KPH Pemalang.
\end{abstract}

Kata kunci : BKPH Slarang, faktor penyebab, partisipasi masyarakat, pengendalian kebakaran hutan

\footnotetext{
${ }^{1}$ Departemen Silvikultur, Fakultas Kehutanan dan Lingkungan, IPB University

* Penulis korespondensi:

e-mail: saharjobambangh@gmail.com

${ }^{2}$ Mahasiswa Sarjana Departemen Silvikultur, Fakultas Kehutanan dan Lingkungan, IPB University
} 


\section{PENDAHULUAN}

Hutan merupakan suatu kesatuan yang terdiri dari hamparan lahan yang berisi sumber daya alam hayati yang didominasi oleh pepohonan dalam kesatuan lingkungannya, yang satu dengan yang lainnya tidak dapat dipisahkan (UU No. 41 Tahun 1999). Hutan memiliki nilai dan peranan penting bagi kehidupan manusia sehingga harus dilindungi dan dimanfaatkan secara bijak. Namun, kondisi hutan di Indonesia saat ini tampak memprihatinkan dengan adanya berbagai macam gangguan, salah satunya yaitu kebakaran hutan. Menurut Peraturan Menteri Lingkungan Hidup dan Kehutanan Republik Indonesia Nomor P.32/MenLHK/Setjen /Kum.1/3/2016 tentang pengendalian kebakaran hutan dan lahan menyatakan bahwa pengendalian kebakaran hutan meliputi usaha/kegiatan/tindakan pengorganisasian, pengelolaan sumberdaya manusia dan sarana prasarana serta operasional pencegahan, pemadaman, penanganan pasca kebakaran, dukungan evakuasi dan penyelamatan, dan dukungan manajemen pengendalian kebakaran hutan dan/atau lahan. Selain itu menurut Saharjo (2003) kebakaran hutan merupakan kejadian pembakaran yang penjalarannya bebas pada areal yang tidak direncanakan serta mengonsumsi bahan bakar alam dari hutan seperti serasah, rumput, ranting/cabang pohon mati, pohon mati yang tetap berdiri, log, tunggak pohon, gulma, semak belukar, dedaunan, dan pohon-pohon. Kebakaran hutan merupakan salah satu bentuk gangguan hutan yang sering terjadi.

Kebakaran hutan di Indonesia setiap tahunnya sering terjadi di seluruh wilayah Indonesia saat musim kemarau. Penyebab kebakaran hutan dan lahan bersifat alami maupun perbuatan manusia sehingga terjadinya proses penyalaan dan pembakaran bahan bakar hutan dan lahan. Faktor penyebab kebakaran hutan di Indonesia yaitu disebabkan oleh faktor alam dan faktor manusia. Faktor alam sangat kecil pengaruhnya dibandingkan faktor manusia yang hampir $100 \%$ dari kejadian kebakaran hutan baik disengaja ataupun tidak disengaja, seperti api yang digunakan untuk pembukaan lahan (Zulkifli et al. 2017). Kebakaran hutan menimbulkan kerugian yang besar apabila tidak dilakukan pengendalian kebakaran hutan dengan baik. Kegiatan pengendalian kebakaran hutan merupakan semua aktivitas untuk melindungi hutan dari kebakaran liar. Salah satu upaya yang dilakukan adalah mengetahui penyebab terjadinya kebakaran dan ketersediaan alat serta upaya pengendalian secara optimal.

Kondisi geografis potensi sumberdaya hutan di Kabupaten Pemalang terletak di antara $109^{\circ} 17^{\prime} 30^{\prime \prime}$ BT s/d 10940'30" BT dan 852'30" LS s/d 7²0'00" dengan luas total wilayah sebesar 24.392,67 Ha meliputi kawasan hutan yang berada di wilayah Kabupaten Tegal 8.494,30 Ha dan Kabupaten Pemalang seluas 15.898,37 Ha (Perhutani 2013). Wilayah hutan KPH Pemalang dan sekitarnya beriklim tropis yang sangat cocok untuk ditanami tegakan jenis jati. Curah hujan rata-rata di Kabupaten Pemalang tahun 2019 sebesar 2.156 mm/ tahun. Kebakaran Hutan yang terjadi di BKPH Slarang KPH Pemalang Jawa Tengah terjadi setiap tahunnya sekitar musim-musim kemarau. Perlu adanya peran masyarakat dalam pengendalian kebakaran hutan terhadap pencegahan kebakaran hutan di BKPH Slarang, KPH Pemalang, Jawa Tengah. Penelitian ini bertujuan untuk menganalisis faktor penyebab terjadinya kebakaran hutan dan mengkaji upaya dalam pengendalian kebakaran hutan serta partisipasi masyarakat dalam pengendalian kebakaran hutan di BKPH Slarang, KPH Pemalang, Jawa Tengah.

\section{METODE PENELITIAN}

\section{Waktu dan Tempat Penelitian}

Penelitian dilakukan di BKPH Slarang, KPH Pemalang, Jawa Tengah, Desa Pegongsoran dan Desa Surajaya. Penelitian ini dilaksanakan pada bulan Agustus-September 2020.

\section{Alat dan Bahan Penelitian}

Alat yang digunakan dalam penelitian ini adalah laptop, kamera, alat perekam, alat tulis, lembar kuesioner (tally sheet), software Microsoft Excel, dan Microsoft Word. Bahan dan data yang diperlukan dalam penelitian, yaitu data profil KPH Pemalang, profil lokasi desa penelitian, frekuensi atau jumlah kebakaran hutan BKPH Slarang selama 5 tahun terakhir (2015-2019), data curah hujan BKPH Slarang 5 tahun terakhir (2015-2019), data luas kebakaran BKPH Slarang 5 tahun terakhir (20152019), data pengelolaan hutan dalam pengendalian kebakaran hutan dan daftar kuisioner untuk pengumpulan data hasil wawancara dari masyarakat.

\section{Metode Pengumpulan Data}

Pengumpulan data primer dilakukan dengan menggunakan metode wawancara terhadap BKPH Slarang sebagai informan dan wawancara terhadap masyarakat desa kajian sebagai responden dengan bantuan kuesioner. Penetapan responden dilakukan dengan metode snowball sampling technique yaitu peneliti mengenal informan kunci (Key Person Interviews) kemudian informan kunci memperkenalkan kepada responden lain (Bungin 2011). Penunjukan informan kunci dilakukan oleh kepala BKPH (Asper) Slarang dan ketua Lembaga Masyarakat Desa Hutan (LMDH). Responden lain adalah masyarakat sekitar hutan yang sering berinteraksi di dalam kawasan hutan yaitu anggota LMDH atau penggarap lahan (pesanggem). Data sekunder diperoleh melalui penelusuran dokumen agar diperoleh dokumen yang berkaitan dengan penyebab kebakaran hutan, upaya pengendalian kebakaran hutan di BKPH Slarang, KPH Pemalang. Dokumen tersebut yaitu profil KPH Pemalang, profil desa kajian, dan frekuensi atau jumlah kebakaran hutan 5 tahun terakhir, data curah hujan 5 tahun terakhir, data luas kebakaran hutan 5 tahun terakhir, dan data pendukung lainnya.

\section{Prosedur Analisis Data}


Pendekatan kualitatif digunakan dalam penelitian ini untuk mengkaji dan mendeskripsikan faktor penyebab kebakaran hutan dan upaya pengendalian kebakaran hutan di BKPH Slarang, KPH Pemalang. Analisis data dilakukan dengan mengidentifikasi data hasil wawancara, observasi lapang, dan penelusuran dokumen. Data dianalisis menggunakan metode deskriptif kualitatif yaitu dilakukan dengan cara mendeskripsikan secara menyeluruh data yang diperoleh selama proses penelitian. Analisis data deskriptif kualitatif menggunakan model Miles dan Huberman. Aktivitas analisis data ini meliputi data reduction (reduksi data), data display (penyajian data), dan data conclusion drawing/verification (penarikan kesimpulan).

\section{HASIL DAN PEMBAHASAN}

\section{Kondisi Umum Lokasi Penelitian}

Kesatuan Pemangku Hutan (KPH) Pemalang adalah salah satu unit manajemen di wilayah Divisi Regional Jawa Tengah. Berdasarkan letak geografis, KPH Pemalang terletak antara $109^{\circ} 17^{\prime} 30^{\prime \prime}$ BT sampai dengan $109^{\circ} 40^{\prime} 30^{\prime \prime}$ BT dan 8'52’30” LS s/d 7²0’00”. KPH Pemalang memiliki luas wilayah seluas 24.392,67 Ha yang terdiri atas Kawasan hutan di KPH Pemalang terdiri dari Hutan Produksi 21.044,1 Ha, Kawasan Perlindungan 2.663,0 Ha dan Kawasan untuk penggunaan lain 685,57 Ha yang tersebar pada 6 wilayah Bagian Kesatuan Pemangkuan Hutan (BKPH) dan 2 wilayah Kabupaten/Kota (Perhutani 2009). Luasan wilayah hutan KPH Pemalang disajikan dalam Tabel 1.

Berdasarkan topografinya kawasan hutan KPH Pemalang dengan konfigurasi lapangan datar, berombak, miring, dan curam. Keadaan tanah kawasan hutan KPH Pemalang berjenis latosol, mediteran, aluvial, dan grumusol. Umumnya tanahnya bertekstur sedang hingga liat dan strukturnya remah hingga berkumpal dan sebagian besar berjenis latosol. Kawasan hutan terletak pada ketinggian 15-270 $\mathrm{m} \mathrm{dpl}$, beriklim tipe $\mathrm{C}$ dan $\mathrm{D}$ menurut Schmidt dan Ferguson. Lingkungan dengan tipe iklim tersebut sangat cocok untuk ditanami tegakan jenis Jati (Tectona grandis). Temperatur rata-rata di wilayah Kabupaten Pemalang yaitu $27,1^{\circ} \mathrm{C}$ dan curah hujan ratarata sebesar $2.731 \mathrm{~mm} /$ tahun.

\section{Keadaan Wilayah Penelitian}

Desa Pegongsoran berada di Kecamatan Pemalang, BKPH Slarang, KPH Pemalang, Jawa Tengah. Desa

Tabel 1 Luas wilayah kerja KPH Pemalang

\begin{tabular}{clcc}
\hline No & BKPH & Luas wilayah & Kabupaten \\
\hline 1 & Jatinegara & $3.717,00$ & Tegal \\
2 & Kedungjati & $4.777,30$ & Tegal \\
3 & Cipero & $4.248,20$ & Pemalang \\
4 & Slarang & $3.610,30$ & Pemalang \\
5 & Bantarsari & $3.542,00$ & Pemalang \\
6 & Sokawati & $4.497,87$ & Pemalang \\
\hline
\end{tabular}

Sumber: KPH Pemalang 2015-2019
Pengongsoran memiliki luas sebesar 122.492 Ha. Batasbatas wilayah desa Pegongsoran sebelah utara berbatasan dengan Desa Sungapan dan Kelurahan Paduraksa, sebelah selatan berbatasan dengan Surajaya dan Desa Peguyangan, sebelah barat berbatasan dengan Desa Surajaya, dan sebelah timur berbatasan dengan Desa Sungapan dan Desa Penggarit. Desa Pegongsoran memiliki penduduk berjumlah 5.391 jiwa (Desa Pegongsoran 2019).

Desa Surajaya berada di kecamatan Kecamatan Pemalang, BKPH Pemalang, KPH Pemalang, Jawa Tengah. Desa Surajaya memiliki luas 570.265 Ha. Batasbatas wilayah Desa Surajaya sebelah utara berbatasan dengan Kelurahan Paduraksa dan Desa Kramat, sebelah selatan berbatasan dengan Desa Lenggerong, sebelah barat berbatasan dengan Desa Banjarmulya, dan sebelah timur berbatasan dengan Kelurahan Pegongsoran. Desa Surajaya memiliki penduduk berjumlah 9.925 jiwa. (Desa Surajaya 2018).

\section{Kondisi Pendidikan dan Mata Pencaharian}

Tingkat pendidikan mayoritas masyarakat Desa Pegongsoran adalah tamatan SD dengan persentase sebesar 39,80\% dan Desa Surajaya mayoritas tingkat pendidikannya adalah tamatan SD sebesar $43,47 \%$. Mata pencaharian penduduk Desa Pegongsoran dan Desa Surajaya mayoritas adalah petani dan buruh yang disajikan pada Tabel 2.

\section{Tingkat Kerawanan Kebakaran Hutan Berdasarkan Curah Hujan}

Tingkat kerawanan suatu areal terhadap kebakaran dapat dilihat dari segi cuaca. Kondisi cuaca di BKPH Slarang dapat dilihat dari intensitas curah hujan yang terjadi setiap tahunnya. Berdasarkan gambar 1 rata-rata curah hujan tertinggi terjadi pada bulan Februari tahun 2018 sebesar $634 \mathrm{~mm}$. Kebakaran yang terjadi di BKPH Slarang umumnya terjadi pada bulan Juni sampai September yang memiliki tingkat curah hujan yang rendah. Hal ini sesuai dengan frekuensi terjadinya kebakaran pada tahun 2016 paling sedikit yaitu sebanyak 1 kali. Pada bulan Juni tahun 2015, 2017, 2018, dan 2019

Tabel 2 Klasifikasi jenis mata pencaharian desa penelitian

\begin{tabular}{lcc}
\hline \multirow{2}{*}{$\begin{array}{l}\text { Mata } \\
\text { pencaharian }\end{array}$} & \multicolumn{2}{c}{ Jumlah (jiwa) } \\
\cline { 2 - 3 } & $\begin{array}{c}\text { Desa } \\
\text { Pegongsoran }\end{array}$ & $\begin{array}{c}\text { Desa } \\
\text { Surajaya }\end{array}$ \\
\hline Petani & 506 & 4415 \\
Buruh & 317 & 561 \\
PNS & 35 & 21 \\
TNI/Polri & 7 & 11 \\
Pedagang & 237 & 432 \\
Tukang & 26 & 125 \\
Pensiunan & 22 & 20 \\
Swasta & 555 & 456 \\
Lain-lain & 176 & 184 \\
\hline
\end{tabular}

Sumber: Monografi Desa Pegongsoran 2019 dan

Desa Surajaya 2018 
terjadi hujan dengan intensitas rendah dan tidak ada sama sekali. Hal ini memicu terjadinya kebakaran hutan seperti pada tabel 3 yang menunjukkan frekuensi terjadinya kebakaran pada tahun tersebut sebanyak 4, 1, 2, 3, dan 2 kali. Curah hujan yang rendah ini (kurang dari $60 \mathrm{~mm}$ ) akan menyebabkan frekuensi kebakaran hutan yang meningkat (Syaufina 2008). Frekuensi terjadinya kebakaran paling tinggi yaitu pada tahun 2015 sebanyak 4 kali dengan luas areal yang terbakar sebesar $11.40 \mathrm{Ha}$ dengan kerugian sebesar Rp 50.234.000.

Berdasarkan hasil wawancara dengan pihak Perhutani, kebakaran yang terjadi di BKPH Slarang, KPH Pemalang biasanya terjadi pada bulan-bulan kering. Hal tersebut sesuai dengan pernyataan Syaufina (2008) yang menyatakan bahwa peningkatan kebakaran hutan terjadi pada bulan-bulan dengan curah hujan yang rendah. Curah hujan yang rendah dan suhu yang tinggi, menyebabkan bahan bakar cepat mengering dan mudah terbakar.

\section{Faktor Penyebab Terjadinya Kebakaran}

Hasil wawancara dengan masyarakat sekitar hutan menyatakan bahwa penyebab terjadinya kebakaran

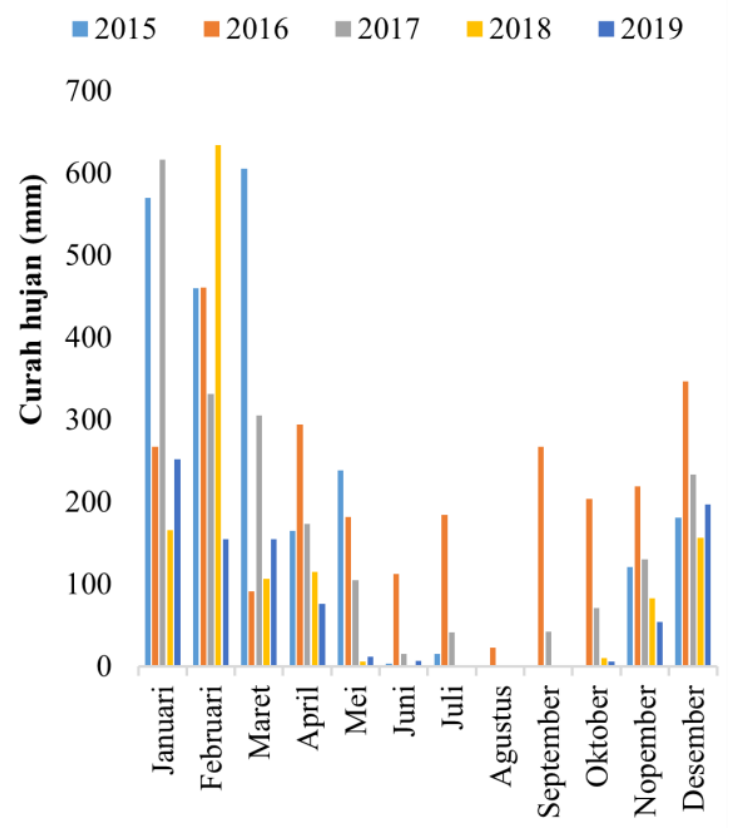

Gambar 1 Rata-rata curah hujan di BKPH Slarang dalam kurun waktu 2015-2019

Tabel 3 Frekuensi kebakaran, luas kebakaran, dan rata-rata kerugian kebakaran di $\mathrm{BKPH}$ Slarang

\begin{tabular}{cccc}
\hline Tahun & $\begin{array}{c}\text { Frekuensi } \\
\text { Kebakaran }\end{array}$ & $\begin{array}{c}\text { Luas } \\
\text { Kebakaran } \\
(\mathrm{Ha})\end{array}$ & $\begin{array}{c}\text { Rata-rata } \\
\text { kerugian (Rp) }\end{array}$ \\
\hline 2015 & 4 & 11.10 & 50.234 .000 \\
2016 & 1 & 3.00 & 9.000 .000 \\
2017 & 2 & 5.50 & 16.500 .000 \\
2018 & 3 & 8.00 & 15.600 .000 \\
2019 & 2 & 3.00 & 3.375 .000 \\
\hline \multicolumn{5}{l}{ Sumber data: BKPH Slarang 2015-2019 }
\end{tabular}

dikarenakan adanya puntung rokok, perburuan hewan, iseng, dan serasah kering. Persentase penyebab kebakaran di BKPH Slarang dapat dilihat dari gambar 2.

Pembersihan Lahan Oleh Masyarakat Sekitar Hutan di BKPH Slarang

Kegiatan pembersihan atau penyiapan lahan yang dilakukan oleh penggarap lahan (pesanggem) yang berada di Desa Pegongsoran dan Desa Surajaya dapat dibedakan menjadi 2, yaitu pembersihan lahan yang dilakukan dengan cara bakar (burning) dan pembersihan lahan tanpa bakar (no burning). Kegiatan pembersihan lahan oleh masyarakat dilakukan pada saat musim kemarau. Persentase kegiatan pembersihan lahan kedua masyarakat ditunjukkan pada gambar 3 .

\section{Upaya Pengendalian Kebakaran}

Mengacu pada Peraturan Menteri Kehutanan No. P.32/Menlhk/Setjen/Kum.1/3/2016 menyatakan bahwa pengendalian kebakaran hutan dan lahan yang disebut Dalkarhutla meliputi usaha/kegiatan/tindakan pengorganisasian, pengelolaan sumber daya manusia dan sarana prasarana serta operasional pencegahan, pemadaman, penanganan pasca kebakaran, dukungan evakuasi dan penyelamatan, dan dukungan manajemen pengendalian kebakaran hutan dan / atau lahan.

\section{Pencegahan Kebakaran}

Berdasarkan wawancara dengan masyarakat yang berada di sekitar hutan di wilayah BKPH Slarang, masyarakat yang menerima sosialisasi tentang pengendalian kebakaran di BKPH Slarang, KPH

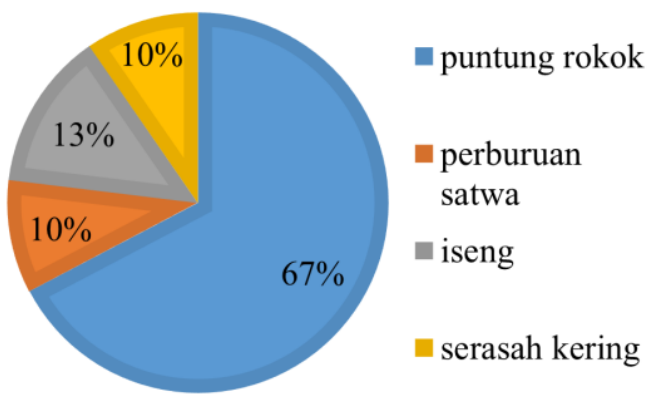

Gambar 2 Presentase penyebab kebakaran hutan di BKPH Slarang

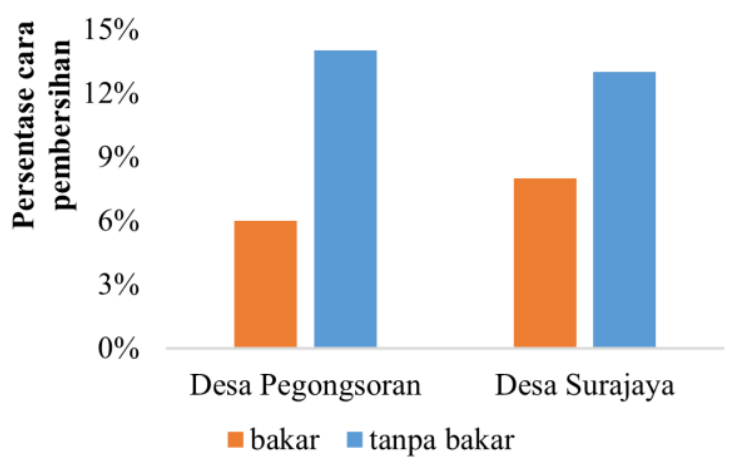

Gambar 3 Cara pembersihan lahan oleh masyarakat Desa Pegongsoran dan Desa Surajaya 
Pemalang sebesar $75 \%$ dan yang tidak menerima sosialisasi sebesar $25 \%$.

\section{Pemadaman Kebakaran}

Kegiatan pemadaman api dilakukan supaya tidak menjalar lebih luas. Metode pemadaman yang digunakan BKPH Slarang adalah pemadaman api secara langsung menggunakan sarana dan prasarana seperti perlengkapan pribadi, gepyok, garpu/garuk, sekop, cangkul, dan sprayer.

Perlunya partisipasi masyarakat dalam pemadaman kebakaran hutan untuk mencegah api menjalar ke wilayah yang lebih luas. Berdasarkan hasil wawancara dengan masyarakat, kegiatan pemadaman dilakukan dengan menggunakan gepyok sebesar $70 \%$, sedangkan masyarakat yang melakukan pemadaman membuat ilaran sebesar 30\% yang ditunjukkan pada Gambar 5 .

\section{Penanganan Pasca Kebakaran}

Penanganan pasca kebakaran merupakan semua usaha, tindakan atau kegiatan yang meliputi inventarisasi, monitoring, dan evaluasi serta koordinasi dalam rangka menangani suatu areal setelah terbakar.

\section{Tingkat Kerawanan Kebakaran Hutan Berdasarkan Curah Hujan}

Tingkat kerawanan suatu areal terhadap kebakaran dapat dilihat dari segi iklim. Iklim dan curah hujan merupakan salah satu komponen dari segitiga lingkungan api. Faktor iklim yaitu suhu, kelembaban, angin, dan curah hujan turut menentukan kerawanan kebakaran. Curah hujan berperan penting dalam kebakaran hutan karena menentukan akumulasi bahan bakar. Curah hujan berpengaruh terhadap kadar air yang terkandung dalam

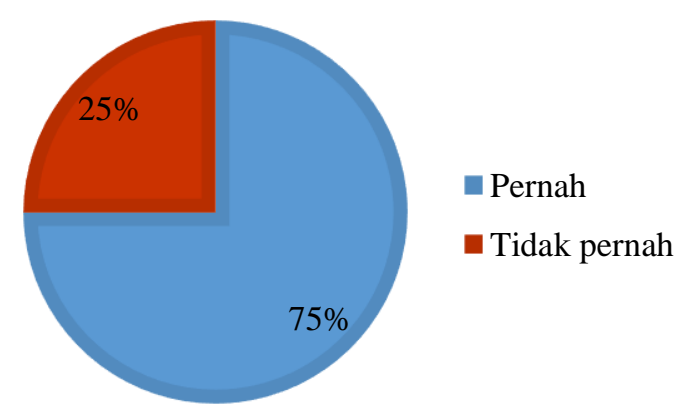

Gambar 4 Presentase masyarakat yang menerima sosialisasi pengendalian kebakaran hutan di BKPH Slarang, KPH Pemalang

Tabel 4 Daftar peralatan pemadaman kebakaran hutan BKPH Slarang

\begin{tabular}{lll}
\hline No & Jenis Alat & Jumlah \\
\hline 1 & Gepyok & 5 \\
2 & Garpu/Garuk & 5 \\
3 & Pompa air & - \\
4 & Sekop & 2 \\
5 & Cangkul & - \\
6 & Sprayer & 1 \\
7 & Sabit & - \\
\hline
\end{tabular}

Sumber Data: BKPH Slarang 2018 bahan bakar, jika kadar air bahan bakar tinggi maka sulit terbakar. Menurut Purbowaseo (2004) faktor curah hujan bisa dilihat dari bulan-bulan yang termasuk curah hujan tinggi dan rendah. Kebakaran yang terjadi di BKPH Slarang umumnya terjadi pada bulan Juli sampai September yang memiliki tingkat curah hujan yang rendah.

Berdasarkan pada gambar 1 rata-rata curah hujan selama 5 tahun terakhir di BKPH Slarang pada bulanbulan kering curah hujan tertinggi pada tahun 2016. Hal ini sesuai dengan frekuensi terjadinya kebakaran pada tahun 2016 paling sedikit yaitu sebanyak 1 kali dengan luas kebakaran sebesar 3.00 Ha dan kerugian sebesar Rp 9.000.000. Menurut Syaufina (2008) curah hujan yang rendah (kurang dari $60 \mathrm{~mm}$ ) mampu menyebabkan frekuensi kebakaran hutan meningkat. Curah hujan berbanding terbalik dengan frekuensi kebakaran hutan dimana semakin tinggi curah hujan memungkinkan terjadinya kebakaran hutan semakin rendah. Curah hujan menurun rata-rata terjadi pada bulan Juni sampai September. Hal ini dapat memicu terjadinya kebakaran hutan. Intensitas terjadinya kebakaran hutan terbanyak pada tahun 2015 yakni sebanyak 4 kali dengan luasan kebakaran 11.10 Ha dan kerugian sebesar Rp 50.234.000.

\section{Faktor Penyebab Terjadinya Kebakaran}

Kebakaran hutan disebabkan oleh dua faktor, yaitu faktor alami dan manusia. Faktor alami disebabkan oleh petir, pengaruh El-Nino yang menyebabkan kemarau panjang, letusan gunung berapi. Faktor manusia antara lain kesengajaan membakar, konflik sosial dan api unggun. Berdasarkan hasil wawancara dengan masyarakat desa sekitar hutan bahwa kebakaran hutan ini disebabkan oleh kelalaian manusia seperti membuang puntung rokok, perburuan satwa, iseng atau sengaja dan ada yang menyatakan akibat akumulasi serasah kering. Persepsi masyarakat mayoritas beranggapan bahwa penyebab terjadinya kebakaran hutan berupa puntung rokok. Hal ini tidak dapat dijadikan acuan dalam menentukan penyebab kebakaran hutan, dikarenakan penyebab kebakaran yang disebabkan oleh puntung rokok sangat kecil. Menurut Apriansyah (2004) melakukan percobaan pembakaran dengan menggunakan puntung rokok menunjukkan hasil bahwa puntung rokok tidak dapat menyebabkan kebakaran hutan karena bara

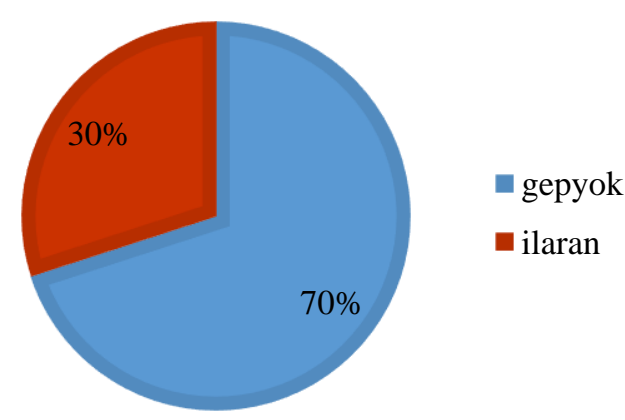

Gambar 5 Presentase partisipasi masyarakat dalam pemadaman kebakaran hutan

puntung rokok tidak cukup panas untuk memanaskan bahan bakar sampai ke titik nyala api. 
Penyebab terjadinya kebakaran hutan juga dikarenakan adanya masyarakat yang iseng atau sengaja membakar dengan kepentingan tertentu. Selain itu kegiatan perburuan satwa babi hutan dapat menyebabkan kebakaran. Kegiatan ini masih sering dilakukan oleh masyarakat di dalam kawasan hutan, cara yang digunakan dalam berburu ini yaitu melakukan pembakaran pada semak-semak agar hewan buruan masuk ke dalam perangkap. Namun terkadang masyarakat meninggalkannya dengan bara api yang masih menyala.

\section{Pembersihan Lahan Oleh Masyarakat Sekitar Hutan di BKPH Slarang}

Penggarap lahan (pesanggem) yang berada di Desa Pegongsoran dan Desa Surajaya melakukan kegiatan penyiapan lahan atau pembersihan lahan untuk melakukan penanaman pertanian. Pembersihan lahan kedua desa ini dengan melakukan dua cara, yaitu cara bakar (burning) dan cara tanpa bakar (no burning). Kegiatan pembersihan lahan oleh masyarakat dilakukan pada musim kemarau. Masyarakat Desa Pegongsoran dan Desa Surajaya lebih menyukai pembersihan lahan dengan cara tanpa bakar dengan persentase masingmasing sebesar $14 \%$ dan $12 \%$. Namun ada beberapa masyarakat Desa Pegongsoran dan Desa Surajaya yang melakukan pembersihkan lahan dengan cara bakar masing-masing $6 \%$ dan $8 \%$. Teknik pembersihan lahan tanpa bakar yang digunakan pada Desa Pegongsoran dan Surajaya hampir sama yaitu dengan pembabatan secara habis semak belukar. Setelah di babat membabat semak belukar atau rerumputan secara habis, kemudian hasil serasah didiamkan atau dibiarkan membusuk menjadi kompos atau disemprot supaya rumputnya mati. Penggunaan alat sederhana dalam pembersihan lahan pertanian berupa cangkul, arit, dan sabit. Sedangkan pembersihan lahan menggunakan cara bakar (burning) agar mengefisienkan waktu dan estimasi harga yang lebih murah karena setelah dilakukan pembakaran, maka sisa dari pembakaran akan menjadi pupuk yang sangat berguna dalam kesuburan tanah.

\section{Upaya Pengendalian Kebakaran di BKPH Slarang}

Upaya pengendalian kebakaran hutan adalah berbagai kegiatan yang dilakukan untuk mencegah dan membatasi kerusakan hutan yang disebabkan oleh kebakaran. Kegiatan pengendalian kebakaran hutan yang dilakukan oleh pihak BKPH Slarang terdiri dari pencegahan kebakaran, pemadaman kebakaran, dan penanganan pasca kebakaran.

\section{Pencegahan Kebakaran Hutan}

Bentuk pencegahan yang dapat dilakukan oleh pihak BKPH Slarang yaitu melalui sosialisasi atau penyuluhan secara langsung maupun tidak langsung. Bentuk sosialisasi secara langsung diberikan kepada masyarakat pada saat berbagai kegiatan seperti pengajian dan rapat perkumpulan LMDH. Adapun materi yang diberikan berupa informasi bahaya akan terjadinya kebakaran hutan, cara menggunakan api di kawasan hutan, dan lainlain.

Partisipasi masyarakat dalam melakukan kegiatan pencegahan kebakaran hutan sangat diperlukan. Berdasarkan hasil wawancara, diketahui bahwa peningkatan peran masyarakat dalam kegiatan pencegahan kebakaran hutan yang dilakukan oleh BKPH Slarang, Desa Pegongsoran dan Desa Surajaya sudah cukup baik dalam melakukan kegiatan pencegahan kebakaran di BKPH Slarang, KPH Pemalang. Upaya pencegahan yang telah dilakukan oleh BKPH Slarang dalam pencegahan kebakaran hutan antara lain membentuk tim Satdalkarhut yang terdiri dari Polhut dan melibatkan Lembaga Masyarakat Desa Hutan (LMDH), patroli rutin, membuat rambu-rambu larangan membakar hutan serta melakukan pelatihan pengendalian kebakaran hutan bagi petugas satdarkarhut dan masyarakat sekitar hutan. Selain itu juga terdapat menara pantau yang baru saja diresmikan pada tanggal 04 September 2020 setinggi 5 meter, terletak di petak 43 RPH Kramat BKPH Slarang dapat dilihat pada gambar 13. Menara pantau tersebut digunakan untuk membantu memantau ketika terjadinya kebakaran pada daerah BKPH yang ada di Pemalang dan penjagaan dilakukan bergilir setiap waktunya.

\section{Pemadaman Kebakaran Hutan}

Kegiatan pemadaman dilakukan agar kebakaran hutan tidak menyebar lebih luas. Kegiatan dalam memadamkan api, pihak perhutani dan masyarakat sekitar cenderung melakukan metode pemadaman api secara langsung. Metode pemadaman secara langsung adalah aktivitas secara langsung yang berkesinambungan untuk mendinginkan, mengibas, memukul, memindahkan bahan bakar atau memadamkan api dengan syarat api kecil, bahan bakar sedikit, dan kebakaran bawah (Purbowaseso 2004). Sarana dan prasarana dalam kebakaran hutan meliputi perlengkapan pribadi dan perlengkapan regu.

Mengacu pada Peraturan Menteri Lingkungan Hidup Nomor P.32/menLHK/setjen/kum.1/3/2016 tentang pengendalian kebakaran hutan pasal 56 ayat 3 menyebutkan jenis dan jumlah peralatan dalam 1 regu sekurangkurangnya terdiri atas : a) kapak dua fungsi sejumlah 4 unit; b) gepyok sebanyak 8 unit; c) garu tajam sejumlah 6 unit ; d) garu pacul sejumlah 6 unit; e) sekop sejumlah 6 unit; f) pompa punggung sejumlah 10 unit; g) obor sulut tetes sejumlah 1 unit; h) kikir sejumlah 2 unit; dan golok atau parang sejumlah 10 unit. Berdasarkan pengamatan di BKPH Slarang hanya terdapat beberapa alat yang ada dan jumlahnya yang kurang sesuai, peralatan yang tersedia dalam kondisi rusak. Adapun peralatan yang ditemukan seperti gepyok, garpu/garuk, sekop, cangkul, dan sprayer. Peralatan yang ada biasanya mendapatkan bantuan dari pihak Perhutani. Perlengkapan pribadi saat memadamkan api di BKPH Slarang sudah cukup baik, seperti kaos sepatu boot, masker, dan helm (topi pengaman). Jumlah petugas pemadam yang ada di BKPH Slarang sebanyak 28 personil.

Partisipasi masyarakat dalam memadamkan kebakaran hutan di BKPH Slarang KPH Pemalang sangat penting. Berdasarkan hasil wawancara dengan 
masyarakat di Desa Pegongsoran dan Desa Surajaya sebesar 30\% menggunakan teknik ilaran dan $70 \%$ menggunakan gepyok. Pemilihan menggunakan alat gepyok dirasa paling mudah dan cepat. Hal ini dikarenakan keterbatasan alat yang dilapang untuk memadamkan api. BKPH Slarang memiliki LMDH (Lembaga Masyarakat Desa Hutan) juga ikut melakukan patroli bersama yang membantu dalam memadamkan api ketika terjadi kebakaran dan berpengaruh terhadap pengendalian kebakaran hutan sebab organisasi ini langsung berinteraksi kepada masayarakat lainnya. Belum terdapatnya MPA (Masyarakat Peduli Api) sehingga perlu dilakukan pembentukan Masyarakat Peduli Api. Alur koordinasi pemadaman kebakaran hutan di BKPH Slarang biasanya LMDH atau mandor lalu ke mantri lapor ke asper.

\section{Penanganan Pasca Kebakaran Hutan}

Kegiatan penanganan pasca kebakaran hutan di BKPH Slarang KPH Pemalang yaitu membuat laporan tertulis dan penegakkan hukum. Laporan tertulis berisi luas kebakaran, lokasi kebakaran, penyebab kebakaran dan kerugian finansial kebakaran hutan. Setelah itu pembuatan sketsa lokasi dan pemetaan sehingga diperoleh peta kerawanan kebakaran hutan. Penegakan hukum dilakukan untuk menindak pelaku pembakaran hutan. Adapun kendala perhutani yakni sulit mengetahui dan menangkap pelaku pembakaran. Menurut PP 45 tahun 2004 tentang perlindungan hutan, pasal 27 menyebutkan bahwa dalam rangka penanganan pasca kebakaran hutan sebagaimana dimaksud Pasal 20 ayat (1) huruf c. Sanksi pelaku pembakaran adalah tindak pidana dari kepolisian sesuai Undang-Undang atau peraturan yang berlaku. Masyarakat di wilayah hutan di BKPH Slarang ikut berkonstribusi dalam melakukan pemadaman kebakaran hutan, namun masih terdapat masyarakat yang kurang peduli terhadap hal tersebut. LMDH sangat berperan penting dan memberi manfaat untuk merangkul masyarakat sehingga masyarakat ikut serta dalam memadamkan dan mencegah kebakaran hutan.

\section{SIMPULAN DAN SARAN}

\section{Simpulan}

Kebakaran hutan yang terjadi di BKPH Slarang merupakan kebakaran yang terjadi setiap tahunnya. Berdasarkan hasil wawancara dengan pihak BKPH Slarang dan masyarakat sekitar hutan mengatakan bahwa penyebab kebakaran hutan yakni membuang puntung rokok sebesar $73 \%, 10 \%$ perburuan satwa babi hutan, $13 \%$ iseng dan ada yang menyatakan akibat akumulasi serasah kering sebesar $10 \%$. Adapun upaya pengendalian kebakaran hutan yang dilakukan pihak BKPH Slarang dengan penyuluhan atau sosialisasi, pelatihan pemadaman kebakaran, papan peringatan, dan menara pantau. Sarana dan prasana yang ada dalam kegiatan pemadaman api masih kurang, serta kondisinya yang rusak. Kegiatan penanganan pasca kebakaran hutan di BKPH Slarang yaitu membuat laporan tertulis dan penegakkan hutan. Laporan tertulis berisi berisi luas kebakaran, lokasi kebakaran, penyebab kebakaran dan kerugian finansial kebakaran hutan. Kejadian kebakaran dengan frekuensi sebanyak 4 kali dan luas hutan yang terbakar seluas $11.10 \mathrm{Ha}$ terjadi pada tahun 2015 mengalami kerugian sebesar Rp 50234 000. Peran masyarakat dalam pengendalian kebakaran hutan di BKPH Slarang sangat tinggi hal ini dapat dilihat dari pelatihan pemadaman kebakaran adanya Lembaga Masyarakat Desa Hutan (LMDH).

\section{Saran}

Perlu menambahkan sarana dan prasarana pemadaman kebakaran hutan seperti perlengkapan pribadi, peralatan yang digunakan petugas dalam kegiatan pemadaman kebakaran hutan, tangki air. Selain itu juga perlu melakukan penyuluhan atau sosialisasi intensif tentang kebakaran hutan kepada masayarakat dan pembentukan adanya Masyarakat Peduli Api (MPA).

\section{DAFTAR PUSTAKA}

Apriansyah D. 2004. Pengaruh puntung rokok terhadap kebakaran di bawah tegakan Acacia mangium di HPHHTI PT. Musi Hutan Persada Sumatera Selatan (ID): PT Musi Hutan Persada.

Brown AA, Davis KP. 1973. Forest Free Control \& Use. New York (US): McGraw Hill Company.

Bungin. 2011. Penelitian Kualitatif: Komunikasi, Ekonomi, Kebijakan Publik,dan Ilmu Sosial Lainnya. Jakarta(ID): Kencanan Prenada Media Grup.

Desa Pegongsoran. 2019. Data Monografi Desa Pegongsoran. Pemalang (ID): Pemerintah Daerah Pemalang.

Desa Surajaya. 2018. Data Monografi Desa Surajaya. Pemalang (ID): Pemerintah Daerah Pemalang.

Husaeni EA. 2003. Prinsip Pengendalian Kebakaran Hutan. Pengetahuan Dasar Pengendalian Kebakaran Hutan. Bogor(ID): Fakultas Kehutanan Institut Pertanian Bogor. hlm 167-172.

[KemenLHK] Kementerian Lingkungan Hidup dan Kehutanan Republik Indonesia. 2016. Peraturan Menteri Lingkungan Hidup dan Kehutanan. Nomor p.32/menLHK/Setjen/Kum.1/3/2016. Tentang Pengendalian Kebakaran Hutan dan Lahan. Jakarta (ID): KementerianLHK.

[PERHUTANI] Perum Perhutani KPH Pemalang. 2019. Laporan Tahunan periode 2015-2019. Pemalang (ID): PERHUTANI.

Muhadjir N. 1992. Metodologi Penelitian Kualitatif.Telaah Positivistik, Rasionalistik, Phenomenologik, Realisme Metaphisik. Yogyakarta (ID) : Penerbit Rake Sarasin.

Peraturan Pemerintah Republik Indonesia Nomor 45 Tahun 2004. Tentang Perlindungan Hutan. Jakarta (ID): Sekretariat Jendral Departemen Kehutanan.

Purbowaseso B. 2004. Pengendalian Kebakaran hutan. Jakarta (ID): PT. RinekaCipta. 
Saharjo BH. 2003. Sumber Api. Pengetahuan Dasar Pengendalian Kebakaran Hutan. Bogor(ID): Fakultas Kehutanan IPB.

Saharjo BH, Adinugroho WC, Suryadiputra, Labueni S. 2005. Panduan Pengendalian Kebakaran Hutan dan Lahan Gambut. Bogor(ID): Wetlands Internasional

Sitorus MTF. 1998. Penelitian Kualitatif : Suatu Perkenalan. Bogor (ID): Dokis.

Sugiyono. 2005. Memahami Penelitian Kualitatif. Bandung (ID): CV Alfabeta.

Sugiyono. 2007. Memahami Penelitian Kualitatif. Bandung(ID): CV. Alfabeta.
Susanty SC. 2009. Potensi kebakaran hutan di Taman Nasional Gunung Gede Pangrango berdasarkan curah hujan dan sumber api [skripsi]. Bogor (ID): Institut Pertanian Bogor.

Syaufina L. 2008. Kebakaran Hutan dan Lahan di Indonesia, Perilaku Api, Penyebab dan Dampak Kebakaran. Malang(ID): Bayumedia.

Zulkifli, Ismail, Kamarubayana L. 2017. Studi pengendalian kebakaran hutan di wilayah Kelurahan Merdeka Kecamatan Samboja Kalimantan Timur. Jurnal AGRIFOR 16(1): 141150. 